\title{
Pulmonary embolism in non-brain tumor patients after surgery-a retrospective study in China
}

\author{
Ren-Xiong Chen, Hong-Zhi Wang*, Jun Dong, Hong Ren, Xiao-Jie Chen, Jia-Xuan Xu, Yong Yang \\ and Guo-Dong Wang
}

\begin{abstract}
Background: The incidence rate of pulmonary emboli (PE) is high in tumor patients; however, the morbidity and mortality associated with the development of PE after tumor surgery are unknown. We studied the clinical profiles and outcomes of patients with PE after non-brain tumor surgery.

Methods: We retrospectively screened 55,967 patients who underwent non-brain tumor surgery at the Peking University Cancer Hospital from January 2008 to June 2015. Among them, 76 patients who were diagnosed with PE were enrolled in our study. Factors impacting the overall survival at 90 days were analyzed. A Kaplan-Meier curve was plotted for time to death or until day 90. Cox proportional hazard modeling was performed for univariate- and multivariate-adjusted factor analyses.

Results: The morbidity rate was approximately 135.8 per 100,000 non-brain tumor surgery patients (possibly underestimated). When treated, seven patients had major bleeding, and 14 patients had clinically relevant non-major bleeding, which represented 9.2 and $18.4 \%$ of all the patients, respectively. The 3-month overall mortality rate was $11.8 \%$ in our study. The Acute Physiology and Chronic Health Evaluation II (APACHE II) score and platelet distribution width (PDW) were independent risk factors for the prognosis of PE after nonbrain surgery ( $P$ values of 0.001 and 0.016 , respectively).

Conclusions: Treatment of PE in non-brain tumor surgical patients remained a challenge due to the high bleeding rate. The APACHE II score and PDW were independent prognostic factors of survival in patients with PE after non-brain tumor surgery; however, the study power was limited.
\end{abstract}

Keywords: Pulmonary embolism, Tumor patients, Surgery

\section{Background}

Venous thromboembolism (VTE) includes deep vein thrombosis (DVT) and pulmonary embolism (PE). Pulmonary emboli account for an increasing proportion of venous thromboemboli with increasing patient age. Venous thromboembolism is the third most common cardiovascular disease [1, 2]. There are approximately $300,000-600,000$ cases per year in the USA, resulting in 60,000-100,000 deaths each year [3]. Pulmonary embolism-related deaths in the USA may exceed

\footnotetext{
* Correspondence: doctorwhz@163.com

Critical Care Medicine, Key Laboratory of Carcinogenesis and Translational Research (Ministry of Education), Peking University Cancer Hospital and

Institute, Beijing 100142, China
}

myocardial infarction-related and stroke-related deaths [4]. Although less common in certain regions, such as Asia, venous thromboembolism is a worldwide problem, particularly in people with known risk factors $[5,6]$. In China, the overall annual incidence of PE is 3.9 per 100,000 individuals and the hospital mortality rate associated with $\mathrm{PE}$ is $23.8 \%$ [5].

Surgery and malignancy increase the risk of VTE $[7,8]$. The risk of VTE increases over 90-fold during the first 6 weeks after cancer surgery, compared with that observed in healthy controls, and is second only to the risk of VTE after hip or knee replacement surgery [9]. The risk of venous thrombosis in cancer patients depends on the tumor type and stage, treatment 
measures, and patient-associated factors [10]. The mechanisms may involve mucin production by tumors, exposure of tissue factor-rich surfaces and tissue factor-bearing microparticles, cysteine proteinase production leading to thrombin generation, and local hypoxia [11, 12].

However, previous studies have not analyzed patients according to their status, e.g., medical or surgery patients. Because of the high risk of bleeding, therapy for patients with PE after surgery is different from medical patients. The aim of this study was to explore the clinical profiles and outcomes of patients with PE after non-brain tumor surgery.

\section{Methods}

\section{Study population}

From January 2008 to June 2015, 55,967 patients who underwent surgery for the treatment of tumors at the Peking University Cancer Hospital were retrospectively screened. The diagnosis of PE was made according to the American College of Chest Physicians, ninth edition (ACCP 9th Ed.) guidelines. A total of 76 cases were included for analysis in our study.

\section{Definitions}

Patients who underwent fibrinolysis received a single weight-based intravenous administration (over a period of $2 \mathrm{~h}$ ) of the fibrinolytic agent urokinase.

Those patients were administered nadroparin calcium first. We defined adequate anticoagulation treatment as the dose of nadroparin calcium for $0.08-0.1 \mathrm{~mL} / 10 \mathrm{~kg}$, every $12 \mathrm{~h}(\mathrm{q} 12 \mathrm{~h})$, and reduced anticoagulation treatment as less than $0.08 \mathrm{~mL} / 10 \mathrm{~kg}$, q12h.

Bleeding was considered major if it was clinically overt and associated with a decrease of $2 \mathrm{~g}$ per deciliter (or more) according to the hemoglobin level, led to the transfusion of 2 or more units of red blood cells, was retroperitoneal or intracranial, occurred in a critical organ, or contributed to death. Bleeding episodes that were clinically relevant but did not qualify as major (e.g., epistaxis that required intervention, formation of a large hematoma visible on the skin, or spontaneous macroscopic hematuria) were classified as clinically relevant non-major bleeding.

\section{Statistical analyses}

Values are expressed as the means (ranges) unless otherwise stated. The effect of factors influencing the overall survival at 90 days was analyzed. A Kaplan-Meier curve was plotted for time to death or until day 90. Cox proportional hazard modeling was performed for univariateand multivariate-adjusted factor analyses. The forward stepwise method was applied during the multivariate analysis. Statistical analyses were performed using SPSS version 18.0. $P$ values less than 0.05 (two-tailed) were considered significant.

\section{Results}

\section{Patient characteristics}

Seventy-two patients were diagnosed with PE by computed tomographic pulmonary angiography (CTPA). Two patients were diagnosed via positive compression venous ultrasonography with decreased peripheral blood oxygen saturation because CTPA was unsafe for these patients. Two patients died quickly in the general ward (making an examination impossible). In these patients, PE was diagnosed via clinicians with expert clinical experience. The main baseline characteristics of the included patients are presented in Table 1 . The clinical presentations and diagnoses of the included patients are listed in Table 2.

\section{Treatment, bleeding, and recurrence}

All the patients were provided mechanical prophylaxis after surgery. However, only 16 patients received prophylactic anticoagulation drugs before the diagnosis

Table 1 Patients with PE

\begin{tabular}{|c|c|}
\hline Items & Results \\
\hline Age, years (mean $\pm S D$ ) & $64.1 \pm 10.1$ \\
\hline Male/female (number) & $34 / 42$ \\
\hline $\mathrm{BMI}, \mathrm{kg} / \mathrm{m}^{2}($ mean $\pm \mathrm{SD})$ & $26.0 \pm 3.5$ \\
\hline \multicolumn{2}{|l|}{ Tumor (number) } \\
\hline Breast cancer & 20 \\
\hline Digestive system cancer $^{a}$ & 33 \\
\hline Thoracic tumor $^{\mathrm{b}}$ & 18 \\
\hline Genital urinary tract tumor ${ }^{c}$ & 4 \\
\hline Melanoma & 1 \\
\hline \multicolumn{2}{|l|}{ Coexisting conditions (number) } \\
\hline Hypertension & 34 \\
\hline Diabetes & 13 \\
\hline Varicose vein of lower limb & 10 \\
\hline \multicolumn{2}{|l|}{ Accompanying infection (number) } \\
\hline Pulmonary infection & 5 \\
\hline Abdominal infection & 9 \\
\hline Pleural infection & 2 \\
\hline Surgery incision infection & 1 \\
\hline ICU admission (number) & 56 \\
\hline Hemoglobin before surgery, g/L (mean \pm SD) & $131.4 \pm 18.1$ \\
\hline
\end{tabular}

$P E$ pulmonary embolism, $B M I$ body mass index, $S D$ standard deviation a Including 4 cases of esophageal cancer, 12 cases of gastric cancer, 10 cases of colorectal cancer, 4 cases of liver cancer, 2 cases of pancreatic cancer, and 1 case of primary peritoneal carcinoma

${ }^{\mathrm{b}}$ Including 13 cases of lung cancer, 4 cases of benign lung tumors, and 1 case of thymoma

Including two cases of endometrial carcinoma, one case of ovarian cancer, and one case of uterine cancer 
Table 2 Diagnosis of PE

\begin{tabular}{|c|c|}
\hline Diagnosis & Number of patients \\
\hline \multicolumn{2}{|l|}{ Symptoms ${ }^{a}$} \\
\hline Dyspnea & 50 \\
\hline Syncope & 7 \\
\hline Palpitation & 5 \\
\hline Lower leg pain & 6 \\
\hline Cardiac arrest & 5 \\
\hline Chest pain & 2 \\
\hline Asymptomatic & 15 \\
\hline \multicolumn{2}{|l|}{ Electrocardiogram ${ }^{b}$} \\
\hline Sinus tachycardia & 22 \\
\hline S1Q3T3 & 5 \\
\hline ST-T changes & 10 \\
\hline Low voltage & 5 \\
\hline Atrial fibrillation & 3 \\
\hline Normal & 21 \\
\hline \multicolumn{2}{|l|}{ Gas analysis $^{c}$} \\
\hline $\mathrm{PCO}_{2}<35 \mathrm{mmHg}$ & 12 \\
\hline $\mathrm{PO}_{2} / \mathrm{FiO}_{2} \leq 300 \mathrm{mmHg}$ & 57 \\
\hline $\mathrm{Lac} \geq 2 \mathrm{mmol} / \mathrm{L}$ & 19 \\
\hline D-Dimer elevated & 63 \\
\hline Pulmonary artery hypertension ${ }^{d}$ & 3 \\
\hline Positive troponin ${ }^{\mathrm{e}}$ & 2 \\
\hline \multicolumn{2}{|l|}{ Compression venous ultrasonography ${ }^{f}$} \\
\hline Lower extremity venous thrombosis & 32 \\
\hline Internal jugular and subclavian vein thrombosis & 3 \\
\hline APACHE I| score $>15$ & 13 \\
\hline
\end{tabular}

APACHE II score Acute Physiology and Chronic Health Evaluation II score ${ }^{a}$ Some patients had more than one symptom

bData were available for 59 patients

'Data were available for 68 patients

${ }^{\mathrm{d}}$ Data were available for 24 patients

'Data were available for 60 patients

fData were available for 70 patients

of PE. Every patient was provided oxygen after the diagnosis of PE. Among them, six cases underwent tracheal intubation ventilator-assisted breathing; four cases used non-invasive ventilator-assisted breathing initially (and two cases improved); the other two patients finally advanced to tracheal intubation ventilator-assisted breathing.

In this group, two patients did not receive any anticoagulant or thrombolytic agents, and two patients were administered urokinase $(20,000 \mathrm{U} / \mathrm{kg}$ of body weight) for intravenous thrombolysis within $2 \mathrm{~h}$. Sequentially, the patients were administered nadroparin calcium. Among the patients who used anticoagulants as an initial therapy, one patient received fondaparinux because of heparin-induced thrombocytopenia (HIT) after the prevention of anticoagulant therapy with nadroparin calcium, and the others were initially administered nadroparin calcium. Because of the high risk of bleeding after surgery, more than half of the patients in this group received a reduced dosage of anticoagulant therapy.

Thereafter, 33 patients were transitioned to warfarin by mouth or nutrient line when permitted. The international normalized ratio (INR) was monitored. When the INR reached 2.0 or higher for at least $24 \mathrm{~h}$, unfractionated heparin or nadroparin calcium was discontinued. Forty patients continued to use nadroparin calcium as anticoagulation therapy, and one patient used fondaparinux.

The frequency of bleeding is listed in Table 3. During the course of treatment, seven patients experienced major bleeding. Therefore, two patients stopped anticoagulation therapy and five patients decreased the dosage of anticoagulation therapy and were administered a blood transfusion. A total of 14 patients experienced clinically relevant non-major bleeding and were adjusted to a reduced dosage of anticoagulation therapy. Ultimately, all patients stopped bleeding.

Five cases experienced a recurrence of VTE within 3 months. Among them, two cases were administered the intravenous thrombolytic agent urokinase as a remedial treatment and three cases received unfractionated heparin. At the same time, one patient received an inferior vena cava filter after the recurrence of VTE.

\section{Survival analysis}

The patients were followed up for 3 months, and no patients were lost to follow-up. The 3-month mortality rate was $11.8 \%(9 / 76)$. Survival curves are shown in Fig. 1. Age, body mass index (BMI), Acute Physiology and Chronic Health Evaluation II (APACHE II) score, platelet distribution width (PDW), and mean platelet volume divided by platelet (MPV/PLT) were analyzed in the multiple Cox regression analysis. The APACHE II score and PDW were independent risk factors for the prognosis of PE after surgery, and the relative risk values were 1.229 and 1.840 , respectively (Table 4). The area under the curve (AUC) of the APACHE II scores according to the Receiver Operating Characteristic (ROC) curve was 0.923. If the cutoff APACHE II score was 12 , the sensitivity was 1 and the specificity was 0.716 . The AUC of PDW according to the

Table 3 Treatment and bleeding

\begin{tabular}{lll}
\hline Initial therapy (numbers) & Major bleeding & $\begin{array}{l}\text { Clinically relevant } \\
\text { non-major bleeding }\end{array}$ \\
\hline Thrombolysis (2) & 1 & 0 \\
Adequate anticoagulation (31) & 1 & 5 \\
Reduced anticoagulation (41) & 5 & 9 \\
\hline
\end{tabular}




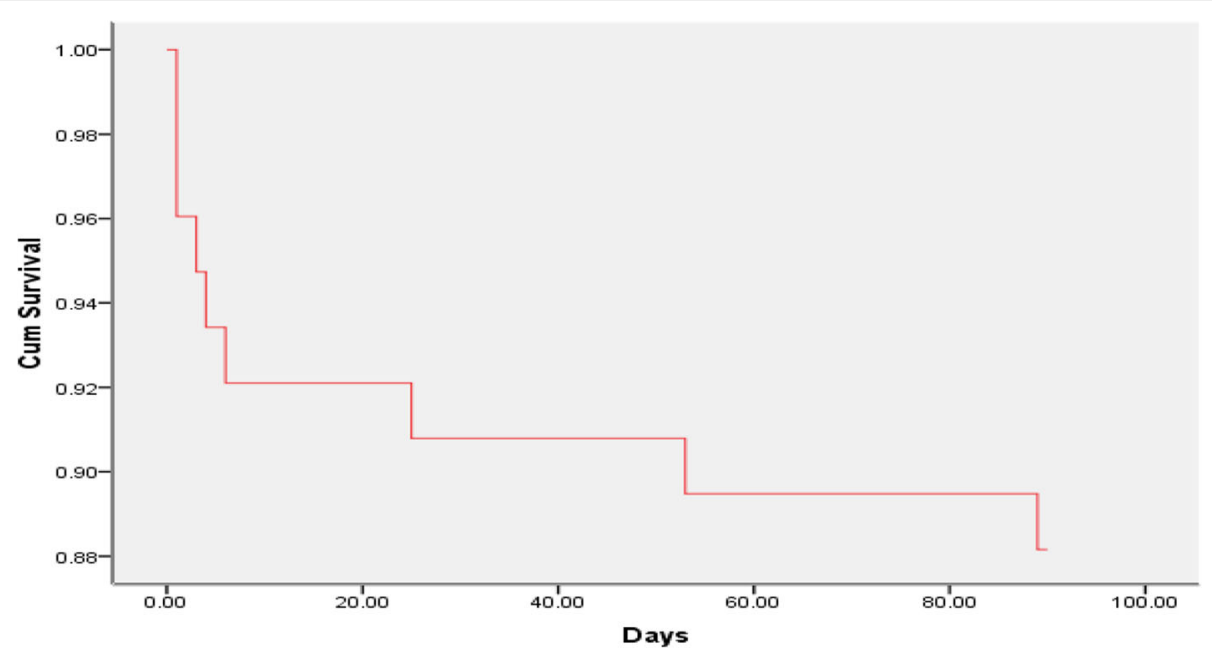

Fig. 1 Kaplan-Meier survival curve of overall survival at 90 days

ROC curve was 0.706 . If the cutoff PDW was 12.4, the sensitivity was 0.778 and the specificity was 0.642 .

\section{Discussion}

The morbidity rate of PE was approximately 135.8 per 100,000 patients in our study. In this study, digestive system cancer (43.4\%) accounted for the largest proportion, followed by breast cancer (26.3\%). These tumors are the most common tumors in our hospital. There were no patients with PE after orthopedic surgery in our hospital during the study years, which might be attributed to positive preventive anticoagulation. The clinical signs and symptoms of PE were non-specific. PE should be suspected based on dyspnea, chest pain, pre-syncope, syncope, and/or hemoptysis. Arterial hypotension and shock were rare but important clinical presentations because they indicated a severely reduced hemodynamic reserve [13]. In our study, dyspnea was the most common presenting symptom, observed in $65.8 \%$ of the patients, followed by a lack of symptoms with decreasing oxygen saturation.

In our study, 72 patients were diagnosed by computed tomographic pulmonary angiography; the other 4 patients could not be safely transported for CTPA. Computed tomographic pulmonary angiography seems to be the most useful method for the diagnosis of PE in critically ill patients. For patients who are so critically ill that transport is unsafe or unfeasible, thrombolytic therapy should be considered if there are clear signs of right

Table 4 Cox regression analysis

\begin{tabular}{llll}
\hline & $\mathrm{RR}$ & $95 \% \mathrm{Cl}$ & $P$ value \\
\hline APACHE II score & 1.229 & $1.127-1.341$ & 0.001 \\
PDW & 1.840 & $1.118-3.027$ & 0.016 \\
\hline
\end{tabular}

ventricular overload according to bedside echocardiography [14]. A positive result on a lower extremity Doppler ultrasound can also be a great help in the decision for treatment.

The choice of treatment for PE depends on the estimated risk of poor outcome. The presence of hypotension is the most significant predictor of poor outcome and is common in patients with massive PE. Currently, in patients with acute PE associated with hypotension who do not have a high risk of bleeding, systemically administered thrombolytic therapy is proposed [15]. For patients with a contraindication to anticoagulation and thrombolytic therapy, surgical embolectomy and catheter-based therapies are options. However, the role of inferior vena cava filters, catheter-based interventions, and surgical embolectomy in life-threatening PE has not yet been absolutely defined. Muriel et al. reported that in patients presenting with VTE and a significant bleeding risk, inferior vena cava filter insertion was associated with a lower risk of PE-related death and a higher risk of recurrent VTE (compared with anticoagulant therapy) [16].

Normotensive patients with evidence of right ventricular (RV) dysfunction as assessed by echocardiography comprise the sub-massive category and have an intermediate risk of poor outcomes. Clinically, patients with sub-massive PE are difficult to distinguish from patients with low-risk PE. Some studies reported that cardiac troponin and brain natriuretic peptide could raise the suspicion that a patient had sub-massive PE [17-19]. The role of fibrinolytic therapy in patients with intermediate-risk PE is controversial. According to one study [20], in patients with intermediate-risk PE, fibrinolytic therapy could reduce early death but increases the 
risk of major bleeding and stroke. During recent years, echocardiography and brain natriuretic peptide (BNP) have not been examined routinely in our hospital. Many data were missing, and we could not stratify non-highrisk PE patients into intermediate-risk and low-risk PE patients. However, this did not influence our treatment of those patients. All patients initially received anticoagulation therapy.

Anticoagulation is the foundation therapy for PE. Low-molecular-weight heparins and fondaparinux were preferred over unfractionated heparin due to their usability [21-23]. All patients with PE in our study had a high risk of bleeding after surgery. We should consider the balance of bleeding risk versus benefit for each patient. However, there was no compelling evidence to validate a scoring system to predict the bleeding risk for patients with VTE. Seven patients experienced major bleeding, and 14 patients experienced clinically relevant non-major bleeding, which accounted for 9.2 and $18.4 \%$ of all patients, respectively. This rate is higher than other reports. As stated above, all patients stopped bleeding via conservative therapy and no bleeding-related deaths occurred.

The 3-month overall mortality rate was previously reported to be approximately 15 to $18 \%$ [24]; the values found in our study were lower. Shock upon presentation was associated with an increase in mortality by a factor of 3-7 [24]. Naess et al. reported that secondary cancer VTE is associated with increased mortality relative to secondary non-cancer VTE and idiopathic VTE [25]. According to a study by Yardan et al. [26], a high MPV/ PLT ratio is associated with RV dysfunction and clinical severity in patients with acute PE and a low MPV/PLT level might be an indicator of low bleeding risk in patients with acute PE. In our study, the APACHE II score and PDW were independent prognostic factors of survival (but not MPV/PLT). The total number of patients in our study was limited, and further research is needed.

The risk of recurrence was particularly high among patients with cancer [14]. The probability of recurrent thromboembolism at 6 months was $17 \%$ in the oralanticoagulant group and $9 \%$ in the low-molecular-weight heparin group [27]. The recurrence rate of VTE was approximately $6.5 \%$ within 90 days in our study. Two patients died after VTE recurrence. In the recurrent patients, two cases received intravenous unfractionated heparin for the treatment of PE and they ultimately survived. This therapy provides another option for patients with recurrence; however, more studies are needed to support this treatment course.

Prophylaxis remained underutilized in patients who were admitted to the hospital with a moderate or high risk of venous thromboembolism and was probably due to the concern regarding the risk of bleeding. We should propose guidelines for the prophylaxis and management of $\mathrm{PE}$ after surgery. More active education is required to raise awareness and to ensure the implementation of these guidelines, which may reduce the burden of PE in patients with tumors after surgery. For patients with a high risk of VTE who are undergoing abdominal or pelvic surgery for cancer, the ACCP 9th Ed. guidelines recommend extended-duration, postoperative, pharmacologic prophylaxis (4 weeks) with LMWH (in contrast to limited-duration prophylaxis) [15].

Currently, the USA has approved one direct thrombin inhibitor (dabigatran) and three factor $\mathrm{Xa}$ inhibitors (apixaban, rivaroxaban, and edoxaban) for the treatment of acute VTE. In a series of important studies, each of these agents has been demonstrated to be at least as safe and effective for the treatment of acute VTE as the traditional bridging strategy (parenteral anticoagulation/warfarin) [28-31]. These drugs do not require any coagulation monitoring in the laboratory and may be accepted by most people in the future.

Several limitations should be mentioned. First, this study was a retrospective study. A prospective study with a control group consisting of patients with PE without tumors and without operations may be more useful. Second, many data were missing, especially data regarding ultrasound cardiogram (UCG). Third, the prevalence of PE may have been underestimated because no autopsies were performed and not all patients underwent CTPA. Finally, the sample size in our COX analysis was small, increasing the risk of a type 2 error due to a lack of statistical power. Larger studies are needed to address the challenging issues during the treatment of tumor surgical patients with PE.

\section{Conclusions}

The treatment of PE in surgical patients with tumors remains a clinical challenge due to the high bleeding rate. The APACHE II score and PDW were independent prognostic factors of survival in patients with PE after non-brain surgery; however, the statistical power was limited.

\section{Abbreviations \\ ACCP 9th Ed.: American College of Chest Physicians, ninth edition; APACHE ॥ score: Acute Physiology and Chronic Health Evaluation II score; AUC: Area under the curve; BMI: Body mass index; BNP: Brain natriuretic peptide; CTPA: Computed tomographic pulmonary angiography; DVT: Deep vein thrombosis; MPV/PLT: Mean platelet volume divided by platelet count; PDW: Platelet distribution width; PE: Pulmonary embolism; ROC: Receiver Operating Characteristic curve; UCG: Ultrasound cardiogram; VTE: Venous thromboembolism}

\section{Acknowledgements}

Not applicable

Funding

The authors received no specific funding for this work. 


\section{Availability of data and materials}

The data will be shared after publishing.

\section{Authors' contributions}

RXC and HZW designed the study. RXC drafted the manuscript. HZW critically revised the manuscript. JD and HR participated in the design of the study and performed the statistical analysis. XJC, JXX, YY, and GDW helped to draft the manuscript. All authors read and approved the final manuscript.

\section{Authors' information}

Ren-Xiong Chen was an attending doctor in the ICU of the Peking University Cancer Hospital and Institute.

Professor Hong-Zhi Wang was the chief of the department.

\section{Competing interests}

The authors declare that they have no competing interests.

\section{Consent for publication}

Not applicable.

\section{Ethics approval and consent to participate}

We received the approval of the Medical Ethical Committee of Peking University Cancer Hospital. A waiver for the requirement for written informed consent was approved by our medical ethical committee because written informed consent could not be obtained and this retrospective study would not have any effect on the included patients.

\section{Received: 16 July 2016 Accepted: 21 December 2016}

\section{Published online: 14 January 2017}

\section{References}

1. Silverstein MD, Heit JA, Mohr DN, Petterson TM, O'Fallon WM, Melton LJ Trends in the incidence of deep vein thrombosis and pulmonary embolism: a 25-year population-based study. Arch intern med. 1998;158:585-93. doi:10.1001/archinte.158.6.585.

2. Heit JA. The epidemiology of venous thromboembolism in the community. Arterioscler thromb vasc biol. 2008;28:370-2. doi:10.1161/ATVBAHA.108. 162545.

3. Beckman MG, Hooper WC, Critchley SE, Ortel TL. Venous thromboembolism: a public health concern. Am j prev med. 2010;38:S495-501. doi:10.1016/j. amepre.2009.12.017.

4. Heit JA, Cohen AT, Anderson FA, OBOIA Group. Estimated annual number of incident and recurrent, non-fatal and fatal venous thromboembolism (VTE) events in the US. Blood. 2005;106:267A

5. Cheuk BL, Cheung GC, Cheng SW. Epidemiology of venous thromboembolism in a Chinese population. Br j surg. 2004;91:424-8. doi:10.1002/bjs.4454.

6. Leizorovicz A, Turpie AG, Cohen AT, Wong L, Yoo MC, Dans A, et al. Epidemiology of venous thromboembolism in Asian patients undergoing major orthopedic surgery without thromboprophylaxis. The SMART study. J thromb haemost. 2005;3:28-34. doi:10.1111/j.1538-7836.2004.01094.x.

7. Buller HR, van Doormaal FF, van Sluis GL, Kamphuisen PW. Cancer and thrombosis: from molecular mechanisms to clinical presentations. J thromb haemost. 2007;5 Suppl 1:246-54. doi:10.1111/j.1538-7836.2007.02497.x.

8. Heit JA, Silverstein MD, Mohr DN, Petterson TM, O'Fallon WM, Melton 3rd L. Risk factors for deep vein thrombosis and pulmonary embolism: a population-based case-control study. Arch Intern Med. 2000;160:809-15. doi: 10.1001/archinte.160.6.809.

9. Sweetland S, Green J, Liu B, Berrington de González A, Canonico M, Reeves $\mathrm{G}$, et al. Duration and magnitude of the postoperative risk of venous thromboembolism in middle aged women: prospective cohort study. BMJ. 2009;339:b4583.

10. Timp JF, Braekkan SK, Versteeg HH, Cannegieter SC. Epidemiology of cancer-associated venous thrombosis. Blood. 2013;122:1712-23. doi:10.1182/blood-2013-04-460121.

11. Varki A. Trousseau's syndrome: multiple definitions and multiple mechanisms. Blood. 2007;110:1723-9. doi:10.1182/blood-2006-10-053736.

12. Zwicker Jl, Liebman HA, Neuberg D, Lacroix R, Bauer KA, Furie BC, et al. Tumor-derived tissue factor-bearing microparticles are associated with venous thromboembolic events in malignancy. Clin cancer res. 2009:15: 6830-40. doi:10.1158/1078-0432.CCR-09-0371.
13. Pollack CV, Schreiber D, Goldhaber SZ, Slattery D, Fanikos J, O'Neil BJ, et al. Clinical characteristics, management, and outcomes of patients diagnosed with acute pulmonary embolism in the emergency department: initial report of EMPEROR (Multicenter Emergency Medicine Pulmonary Embolism in the Real World Registry). J am coll cardiol. 2011;57:700-6. doi:10.1016/j. jacc.2010.05.071.

14. Agnelli G, Becattini C. Acute pulmonary embolism. N engl j med. 2010;363: 266-74. doi:10.1056/NEJMra0907731.

15. Gould MK, Garcia DA, Wren SM, Karanicolas PJ, Arcelus JI, Heit JA, et al. Prevention of VTE in nonorthopedic surgical patients: Antithrombotic Therapy and Prevention of Thrombosis, 9th ed: American College of Chest Physicians Evidence-Based Clinical Practice Guidelines. Chest. 2012;141: e227S-77S. doi:10.1378/chest.11-2297.

16. Muriel A, Jiménez D, Aujesky D, Bertoletti L, Decousus $H$, Laporte $S$, et al. Survival effects of inferior vena cava filter in patients with acute symptomatic venous thromboembolism and a significant bleeding risk. J am coll cardiol. 2014;63:1675-83. doi:10.1016/j.jacc.2014.01.058.

17. Becattini C, Vedovati MC, Agnelli G. Prognostic value of troponins in acute pulmonary embolism: a meta-analysis. Circulation. 2007;116: 427-33. doi:10.1161/CIRCULATIONAHA.106.680421.

18. Jiménez D, Díaz G, Molina J, Martí D, Del Rey J, García-Rull S, et al. Troponin I and risk stratification of patients with acute nonmassive pulmonary embolism. Eur respir j. 2008;31:847-53. doi:10.1183/09031936.00113307.

19. Coutance G, Cauderlier E, Ehtisham J, Hamon M, Hamon M. The prognostic value of markers of right ventricular dysfunction in pulmonary embolism: a meta-analysis. Crit care. 2011;15:R103. doi:10.1186/cc10119.

20. Meyer G, Vicaut E, Danays T, Agnelli G, Becattini C, Beyer-Westendorf J, et al. Fibrinolysis for patients with intermediate-risk pulmonary embolism. $\mathrm{N}$ engl j med. 2014;370:1402-11. doi:10.1056/NEJMoa1302097.

21. Simonneau G, Sors H, Charbonnier B, Page Y, Laaban JP, Azarian R, et al. A comparison of low-molecular-weight heparin with unfractionated heparin for acute pulmonary embolism. The THESEE Study Group. Tinzaparine ou Heparine Standard: Evaluations dans l'Embolie Pulmonaire. N engl j med. 1997;337:663-9. doi:10.1056/NEJM199709043371002.

22. Quinlan DJ, McQuillan A, Eikelboom JW. Low-molecular-weight heparin compared with intravenous unfractionated heparin for treatment of pulmonary embolism: a meta-analysis of randomized, controlled trials. Ann intern med. 2004;140:175-83. doi:10.1016/j.accreview.2004.04.083.

23. Büller HR, Davidson BL, Decousus H, Gallus A, Gent M, Piovella F, et al. Subcutaneous fondaparinux versus intravenous unfractionated heparin in the initial treatment of pulmonary embolism. $\mathrm{N}$ engl j med. 2003; 349:1695-702. doi:10.1056/NEJMoa035451.

24. Tapson VF. Acute pulmonary embolism. N engl j med. 2008;358:1037-52. doi:10.1056/NEJMra072753.

25. Naess IA, Christiansen SC, Romundstad P, Cannegieter SC, Rosendaal FR, Hammerstrøm J. Incidence and mortality of venous thrombosis: a population-based study. J thromb haemost. 2007;5:692-9. doi:10.1111/j. 1538-7836.2007.02450.x.

26. Yardan T, Meric M, Kati C, Celenk Y, Atici A. Mean platelet volume and mean platelet volume/platelet count ratio in risk stratification of pulmonary embolism. Crit care. 2015;19 Suppl 1:328. doi:10.1186/cc14408.

27. Lee AY, Levine MN, Baker RI, Bowden C, Kakkar AK, Prins M, et al. Lowmolecular-weight heparin versus a coumarin for the prevention of recurrent venous thromboembolism in patients with cancer. N engl j med. 2003;349: 146-53. doi:10.1056/NEJMoa025313.

28. Schulman S, Kearon C, Kakkar AK, Mismetti P, Schellong S, Eriksson H, et al. Dabigatran versus warfarin in the treatment of acute venous thromboembolism. N engl j med. 2009;361:2342-52. doi:10.1056/NEJMoa0906598.

29. Agnelli G, Buller HR, Cohen A, Curto M, Gallus AS, Johnson M, et al. Oral apixaban for the treatment of acute venous thromboembolism. $\mathrm{N}$ engl j med. 2013:369:799-808. doi:10.1056/NEJMoa1302507.

30. EINSTEIN-PE Investigators, Büller HR, Prins MH, Lensin AW, Decousus H, Jacobson BF, et al. Oral rivaroxaban for the treatment of symptomatic pulmonary embolism. N engl j med. 2012;366:1287-97. doi:10.1056/ NEJMoa1113572.

31. Hokusai-VTE Investigators, Büller HR, Décousus H, Grosso MA, Mercuri M, Middeldorp S, Prins MH, et al. Edoxaban versus warfarin for the treatment of symptomatic venous thromboembolism. N Engl J Med. 2013;369:1406-15. doi:10.1056/NEJMoa1306638 